\title{
The role of miRNA in motor neuron disease
}

\author{
Min Jeong Kye ${ }^{1,2}$ * and Inês do Carmo G. Gonçalves ${ }^{1,2}$ \\ 1 Institute of Human Genetics, University of Cologne, Cologne, Germany \\ ${ }_{2}^{2}$ Institute for Genetics, University of Cologne, Cologne, Germany
}

Edited by:

Tommaso Pizzorusso, National

Research Council-Neuroscience

Institute, Italy

Reviewed by:

Alexander K. Murashov, East Carolina University, USA

Caterina Bendotti, Istituto di Ricerche

Farmacologiche Mario Negri, Italy

\section{${ }^{*}$ Correspondence:}

Min Jeong Kye, Institute of Human Genetics and Institute for Genetics,

University of Cologne, 50931

Cologne, Germany

e-mail:min.kye@uk-koeln.de
microRNA is a subset of endogenous non-coding RNA. It binds to partially complementary sequences in mRNAs and inhibits mRNA translation by either blocking translational machinery or degrading mRNAs. It is involved in various cellular processes including cell cycle, development, metabolism, and synaptic plasticity. Dysregulation of miRNA expression and function is reported in various diseases including cancer, metabolic disorders as well as neurological disorders. In nervous system, miRNA related pathways play a very important role in development and function of neuronal cells. Moreover, numerous evidences suggest that dysregulated miRNA related pathways contribute to pathology of neurological disorders such as Alzheimer's disease, amyotrophic lateral sclerosis (ALS) and spinal muscular atrophy (SMA). Here, we review current knowledge about the role of miRNAs in motor neuron disorders, especially about two common diseases: SMA and ALS.

Keywords: microRNA, motor neurons, neuromuscular junction, spinal muscular atrophy, amyotrophic lateral sclerosis

\section{INTRODUCTION}

microRNAs (miRNAs) are endogenous non-coding singlestranded RNA molecules that play important roles in eukaryotic gene expression through posttranscriptional regulation (Bartel, 2009). It mainly binds to the $3^{\prime}$-untranslated region ( $3^{\prime}$-UTR) of messenger RNAs (mRNAs) from target protein-coding genes and leads to gene silencing by mRNA cleavage, translational repression and deadenylation (Huntzinger and Izaurralde, 2011). Functional studies indicate that miRNA plays a significant role in a broad range of cellular and developmental processes such as stem cell maintenance (Houbaviy et al., 2003), differentiation (Chen etal., 2004; Naguibneva et al., 2006), cell cycle (Hatfield et al., 2005), development (Hornstein et al., 2005), learning and memory formation (Gao et al., 2010), energy metabolism (Gao et al., 2009), and immune responses (Xiao et al., 2007). miRNAs can only function as part of ribonucleoprotein (RNP) complex called RNA induced silencing complex (RISC), which contains various proteins such as argonautes, fragile $\mathrm{X}$ mental retardation protein (FMRP), Dicer and monkey leukemia virus 10 (MOV10; Jin et al., 2004; Landthaler et al., 2008). Like miRNAs, RISC plays a crucial role in many cellular processes during development and cellular differentiation. For example, deletion of core protein of RISC, Ago2 leads to embryonic lethality in mouse (Morita et al., 2007). Similarly, ablation of Dicer or DiGeorge syndrome critical region gene 8 (DGCR8) also causes developmental arrest in murine embryonic stem cells (Bernstein et al., 2003; Wang et al., 2007). Although it is widely accepted that miRNAs are important for nervous system development and function, a little is known about the role of individual miRNAs in neuron at the moment.

\section{BIOGENESIS AND DECAY OF miRNAs}

The majority of characterized miRNAs are transcribed by RNA polymerase II from their own independent genes or introns of protein-coding genes (Krol et al., 2010). The primary transcript (pri-miRNAs) of miRNA is specifically recognized by microprocessor complex. The microprocessor complex is composed by nuclear ribonuclease III, Drosha, and its binding partner, DGCR8. In this complex, a double stranded RNA-binding protein, DGCR8 recognizes the stem-loop structure in pri-miRNA and Drosha cleaves the pri-miRNA into a $\sim 70$-nucleotide precursor form (premiRNA). Afterward, pre-miRNA is translocated to the cytoplasm by exportin 5 through the nuclear pore complex in a Ran guanosine triphosphate (RanGTP)-dependent process. In the cytoplasm, second RNaseIII containing protein complex cleaves pre-miRNA to $\sim 20$ bp miRNA/miRNA* duplex. This complex is composed of Dicer (RNaseIII), transactivation response RNA binding protein (TRBP), and protein activator of the interferon-induced protein kinase (PACT). One strand of the miRNA duplex is incorporated into the RISC as a mature miRNA (guide strand/miRNA), whereas the other strand (passenger strand/miRNA*) is degraded (Kim et al., 2009).

miRNA can only function in the RISC. The functional core proteins of RISC are mainly composed of Argonaute families (Ago1-4) and glycin-tryptophan protein of $182 \mathrm{kDa}$ (GW182). In RISC, only Agonaute proteins show endonuclease enzymatic activity, which is responsible for mRNA silencing (Huntzinger and Izaurralde, 2011). GW182 proteins are also essential for the RISC function (Eulalio et al., 2008). It inhibits binding of poly-A binding protein (PABPC) to poly-A tail and induces deadenylation, decapping, and decay of mRNAs (Zekri et al., 2009). Additional proteins associated with RISC have been identified such as FMRP, MOV10, and Hu-Antigen R (HuR; Landthaler et al., 2008).

Expression of miRNAs seems to be tightly regulated by sophisticated mechanisms from the biogenesis to decay. Although it is not yet fully understood, the stability of mature miRNA is controlled by endogenous factors such as miRNA degrading enzymes 
and occupancy by target mRNAs. In animal cells, miRNA decay is carried out by the $5^{\prime}$-to- $3^{\prime}$ exoribonuclease 1 and 2 (XRN1 and XRN2; Bail et al., 2010). Interestingly, it seems that binding to their target mRNAs can increase or decrease stability of miRNAs (Chatterjee et al., 2011; Iio et al., 2013). Additionally, environmental factors such as growth factors, cell cycle, and neuronal activity can influence on stability of miRNAs (Ruegger and Grosshans, 2012).

\section{miRNA IN MOTOR NEURONS}

Numerous studies have shown that miRNAs play an important role for nervous system development (Conaco et al., 2006; Akerblom et al., 2012; Zhu et al., 2013). Disturbing miRNA biogenesis pathway by deleting Dicer1 from spinal motor neurons in mouse caused spinal muscular atrophy (SMA) like phenotype (Haramati et al., 2010). More specifically, modifying miR-9 expression in developing motor neurons alters motor neuron subtype specification as well as columnar development of spinal cords in chick embryos (Otaegi etal., 2011a). In this model, miR-9 regulates expression of transcription factor, forkhead box P1 (FoxP1), which plays a crucial role for development and neuronal subtype differentiation in spinal cord (Otaegi etal., 2011b). Another interesting miRNA in motor neuron is miR17-3p. This miRNA directly regulates mRNA translation of oligodendrocyte transcription factor 2 (Olig2), which is an important transcription factor for spinal motor neuron differentiation. The expression of miR-17-3p is repressed by sonic hedgehog (Shh), which results in elevated expression of Olig2. Thus, high amount of Shh will direct neuronal progenitors to differentiate toward motor neurons and decrease interneuron population. Additionally, deletion of miR-17 92 cluster from mouse embryos suggests that this cluster regulates differentiation of interneurons as well as motor neurons in early spinal cord development (Chen et al., 2011). Table 1 summarizes motor neuron related miRNAs discussed in this review.

miRNAs are also important for axonal regeneration process in spinal motor neurons. Ablation of Dicer in sciatic nerve of mouse suggested that functional miRNAs are pivotal for nerve regeneration and axonal re-growth (Wu et al., 2012). In zebrafish, elevated expression of miR-133b after spinal cord injury represses mRNA translation of RhoA. This process promotes functional recovery of motor neuron axons after traumatic injury (Yu et al., 2011). Taken together, we can conclude that miRNAs play a significant role in various processes in motor neurons such as neuronal subtype specification, functional maintenance, and regeneration after injury.

\section{mIRNA AT THE NEUROMUSCULAR JUNCTION}

miRNAs are differentially distributed in neuronal compartments such as soma and neurites (Kye et al., 2007). Numerous miRNAs are presented in axonal compartment and growth cones in cortical and sympathetic neurons (Natera-Naranjo et al., 2010; Sasaki et al., 2013). These data suggests that miRNAs can regulate mRNA translation at the axonal compartments. It seems that miRNAs play a significant role in motor neuron axons, especially at the neuromuscular junction (NMJ). Interestingly, in contrast to vertebrates, Drosophila mutant, who lacks one of the most abundant neuronal
miRNA, miR-124 did not show any strong defect in neuronal production, differentiation, and NMJ morphology. However, the miR-124 Drosophila mutant showed shorter life span, impaired locomotion as well as increased presynaptic neurotransmitter release at the NMJ (Sun et al., 2012). Additionally, miR-8 is also reported as an important miRNA for pre-synaptic bouton formation at the Drosophila NMJ. Repeated neuronal activity represses the expression of miR-8, and it results in elevated neuronal mRNA translation and synaptic growth (Nesler et al., 2013). Drosophila mutants lacking miR-125 or let-7 expression also showed defects in NMJ phenotypes such as delayed maturation of NMJ, smaller size of NMJ, and abnormality in locomotion. Interestingly, these phenotypes are shown only during metamorphosis (Caygill and Johnston, 2008). This implies that miRNAs play a specific role for temporal and spatial regulation of gene expression during development. Another interesting miRNA is miR-310. It regulates synaptic homeostasis at the NMJ by regulating translation of kinesin super family member, Khc-73. miR-310 directly represses the translation of Khc-73 to control neurotransmitter release in motor neurons during larval stages (Tsurudome et al., 2010). Finally, function of miRNA at mammalian NMJ is described in a mouse model for neuromuscular disease, slow-channel congenital myasthenic syndrome (SCS). Axonal expression of miR-124 is elevated in this model compared to the wild type animals. miR124 regulates mRNA translation of $R a b 3 a$ in axon in response to amplified $\mathrm{Ca}^{2+} /$ calpain/cdk5/nitric oxide pathway in muscle cells. In consequence, the elevated expression of miR-124 and reduced expression of Rab3a proteins in nerve terminals decrease neurotransmitter release to the NMJ (Zhu et al., 2013). Taken together, we can conclude that miRNAs are important players for NMJ formation and function as well as maintaining synaptic homeostasis.

Recently, protein and nucleic acids containing vesicles (exosomes) have been suggested as a new molecular mechanism for communication between cells in nervous system (Sharma et al., 2013). They can transfer genetic molecules from donor cells to recipient cells, by which they can change physiology of recipient cells (Valadi et al., 2007). For example, cancer cells release more exosomes than healthy ones. In consequence, it changes physiology of surrounding cells to have more favorable conditions for their metastasis (Grange et al., 2011; Soldevilla et al., 2013). Moreover, various miRNAs are detected in exosomes released from neurons and muscle cells (Forterre et al., 2013; Fruhbeis et al., 2013). These findings strongly suggest that miRNA can function as a signaling molecule for intracellular communication at the NMJ.

\section{TWO COMMON MOTOR NEURON DISEASES; SMA AND ALS PROXIMAL SPINAL MUSCULAR ATROPHY}

Spinal muscular atrophy is a genetically and clinically heterogeneous group of neuromuscular disorders characterized by progressive degeneration of lower alpha motor neurons in the anterior horn of spinal cord (Crawford and Pardo, 1996). Affected individuals exhibit proximal manifestation of muscle weakness and atrophy. With an incidence of 1:6000 1:10000 newborns and a carrier frequency of 1:35, proximal SMA is the leading hereditary cause of infant mortality (Wirth et al., 2006). Due to the highly variable disease severity, four clinical types of SMA are classified 
Table 1 | The list of motor neuron related miRNAs discussed in this review.

\begin{tabular}{|c|c|c|c|c|}
\hline miRNA & Findings & Target genes & $\begin{array}{l}\text { Related disease/model } \\
\text { organism }\end{array}$ & Reference \\
\hline $\operatorname{miR}-8$ & Presynaptic bouton formation/synaptic growth & Lar and Wg & Fruit fly & Nesler et al. (2013) \\
\hline \multirow[t]{6}{*}{$\operatorname{miR}-9$} & $\begin{array}{l}\text { Motor neuron subtype specification/spinal cord } \\
\text { development }\end{array}$ & FoxP1 & Chick & Otaegi etal. (2011a,b) \\
\hline & Dysregulated expression in motor neurons & & SMA/mouse & Haramati etal. (2010) \\
\hline & differentiated from embryonic stem cells & & & \\
\hline & Expression is elevated in induced stem cell & & ALS/cell line (Human) & Zhang etal. (2013) \\
\hline & derived neurons from ALS patient & & & \\
\hline & Axon growth & MAP1B & Mouse & Dajas-Bailador et al. (2012) \\
\hline $\operatorname{miR}-17-3 p$ & Spinal motor neuron differentiation & Olig2 & Mouse & Chen et al. (2011) \\
\hline \multirow[t]{2}{*}{ miR17 92 cluster } & Differentiation of interneuron and motor & & Mouse & Chen et al. (2011) \\
\hline & neurons & & & \\
\hline \multirow[t]{2}{*}{$\operatorname{miR}-21$} & Axonal regeneration & Sprouty2 & Mouse & Strickland et al. (2011) \\
\hline & Spinal cord injury & PTEN and FasL & Rat & Hu et al. (2013) \\
\hline miR-23a, & Expression is increased in skeletal muscle & PGC1- $\alpha$ (miR-23a) & ALS/mouse & Russell etal. (2012) \\
\hline miR-29b, and & from ALS patients and it may cause & & & \\
\hline $\operatorname{miR}-455$ & dysregulation in mitochondrial gene expression & & & \\
\hline $\operatorname{miR}-106$ & Regeneration of NMJ & HDAC4 & ALS/mouse & Williams et al. (2009) \\
\hline \multirow[t]{4}{*}{ miR-124 } & Neurotransmitter release & & Fruit fly & Sun et al. (2012) \\
\hline & Neurotransmitter release at the NMJ & Rab3a & Slow-channel congenital & Zhu etal. (2013) \\
\hline & & & myasthenic & \\
\hline & & & syndrome/mouse & \\
\hline miR-125 and let-7 & NMJ phenotype, delayed maturation, smaller & Abrupt & Fruit fly & Caygill and Johnston (2008) \\
\hline & size, abnormal locomotion, reduced lifespan & & & \\
\hline \multirow[t]{4}{*}{$\operatorname{miR}-132$} & Neuronal morphology and cognition & AChE and p250GAP & ALS/mouse & Edbauer etal. (2010), Shaltiel \\
\hline & & & & et al. (2013) \\
\hline & Splicing of Tau & PTBP2 & Tauopathies/mouse & Smith etal. (2011), Hebert et al. \\
\hline & & & & $(2012)$ \\
\hline miR-132, & Expression is dysregulated in TDP-43 deficient & & ALS and FTLD & Kawahara and Mieda-Sato (2012) \\
\hline miR-143, and & cells. Neurites outgrowth (miR-132) & & (frontotemporal lobar & \\
\hline \multirow[t]{2}{*}{ miR-558 } & & & degeneration)/cell line & \\
\hline & & & (mouse) & \\
\hline $\operatorname{miR}-133 b$ & Spinal cord regeneration & RhoA & Zebrafish & Yu et al. (2011) \\
\hline $\operatorname{miR}-134$ & Neuronal development and dendritogenesis & Pumilio2 & Mouse & Fiore et al. (2009) \\
\hline $\operatorname{miR}-138$ & Axonal regeneration & SIRT1 & Mouse & Liu et al. (2013) \\
\hline miR-310 & Neurotransmitter release at the NMJ & Khc-73 & Fruit fly & Tsurudome et al. (2010) \\
\hline miR-338-3p & Expression is elevated in ALS patients & & ALS/human & De Felice et al. (2012) \\
\hline $\operatorname{miR}-431$ & Axonal regeneration and outgrowth & Kremen1 & Mouse & Wu and Murashov (2013) \\
\hline \multirow[t]{2}{*}{$\operatorname{miR}-451$} & Dysregulated in immune cells (with many & & ALS/mouse & Butovsky et al. (2012) \\
\hline & other miRNAs) & & & \\
\hline
\end{tabular}

based on the age of onset and achieved motor abilities: Type I SMA (Werdnig-Hoffmann), intermediate Type II SMA, mild Type III SMA (Kugelberg-Welander), and Type IV SMA (adult SMA; Pearn, 1980; Wirth et al., 2013).
Survival of motor neuron 1 (SMN1) is the major diseasedetermining gene of SMA. SMA is caused by homozygous deletion or mutation of SMN1 (Lefebvre et al., 1995). This gene is located on the chromosomal region $5 q 11.2-13.3$ in a segment of $\sim 500 \mathrm{~kb}$, 
which includes the telomeric SMN1 and the similar but slightly different centromeric SMN2. SMN2, which is $>99 \%$ identical to $S M N 1$, has only a reduced capacity for correct splicing due to a single silent mutation in exon7. SMN2 produces about $10 \%$ of fulllength SMN2 RNA that encodes a protein identical to the one from SMN1. SMN2, which can vary from one to six copies per genome, is the main modifier of SMA and influences on SMA severity. The severity of SMA can be affected by various genetic factors (Wirth et al., 2013). The human SMN protein is a $38 \mathrm{kDa}$ protein, which forms multi-protein complex with its binding partners, seven Gemins (Gemin 2-8). Self-oligomerization of SMN creates the backbone of the complex (Battle et al., 2006). SMN is ubiquitously expressed and can be found in the nucleus as well as in the axons and dendrites of neurons (Cougot et al., 2008; Akten et al., 2011). In the nucleus, SMN is localized in subcellular structures called gems, where it interacts with a number of proteins that are essential for RNA processing and splicing (Pellizzoni et al., 1998). In the axons, SMN interacts with RNA-binding proteins, such as $\mathrm{HuD}$, and plays a role in RNP trafficking for local mRNA translation (Akten et al., 2011; Fallini et al., 2011). SMN also binds to FMRP (Piazzon et al., 2008), KH-type splicing regulatory protein (KSRP; Tadesse et al., 2008) and fused in sarcoma (FUS; Yamazaki etal., 2012), which are important for miRNA biogenesis and function.

\section{AMYOTROPHIC LATERAL SCLEROSIS}

Amyotrophic lateral sclerosis (ALS) is a progressive neurodegenerative disorder, which leads to death within 2-3 years of onset. It is one of the most common motor neuron diseases occurring $1.7 \sim 2.3$ out of 100,000 person per year in worldwide (Beghi etal., 2006). The symptom of ALS usually starts after age 50 , but it can happen in younger age group. The disease manifests itself by onset of degeneration in specific subset of motor neurons. It progressively spreads to neighboring motor neurons and leads to atrophy of associated muscle tissues (Pratt etal., 2012). The genetic and environmental causes of ALS is still under investigation, but $90 \%$ of them are sporadic or from unknown genetic factors. So far only about $10 \%$ of the cases can be traced to genetic factors (Al-Chalabi et al., 2012). The most well known genetic cause of ALS is mutations in or deletion of Cu/Zn Super Oxide Dismutase 1 (SOD1; Rosen et al., 1993). Only recently, with advanced genomic screening tools, several other genes associated with ALS have been identified including TAR DNA-binding protein (TDP-43), FUS, ALS 2 (ALS2), neurofilament heavy peptide (NEFH; Al-Chalabi etal., 2012) and C9ORF72 (DeJesus-Hernandez et al., 2011; Renton et al., 2011). However, the cellular and pathological mechanisms causing ALS due to mutation or deletion of these genes are still under investigation.

\section{miRNA IN MOTOR NEURON DISEASES}

The role of miRNA and their target genes are intensively studied in cancer field. Studies in cancer cells suggest us that miRNA are involved in many different pathways and their dysregulation can cause various types of cancers (Esteller, 2011; Jansson and Lund, 2012). While the role of individual miRNAs in neurological disorders is not yet fully understood, there are growing evidences that miRNAs play a critical role in neurological disorders, such as miR-206/miR-153 in Alzheimer's disease (Lee et al., 2012; Liang et al., 2012), miR-34b/miR-9/miR-9* in Huntington's disease (Packer etal., 2008; Gaughwin et al., 2011), miR-128a/miR-24/let-7b in mood disorder (Zhou et al., 2009), miR-189 in Tourette's syndrome (Abelson et al., 2005), miR-9 in SMA (Haramati et al., 2010), miR-106/miR-338-3p/miR-451 in ALS (Williams et al., 2009; Butovsky et al., 2012; De Felice et al., 2012), miR-21/miR-431/miR-138 for axonal regeneration for sensory neurons (Strickland et al., 2011; Liu et al., 2013; Wu and Murashov, 2013), and miR-133b/miR-21 for spinal cord injury (Yu et al., 2011; Hu et al., 2013). However, pathological contribution of individual miRNAs to each of these diseases is still under investigation. Especially, our knowledge about the role of miRNAs in motor neuron diseases is very limited. This can be both due to the complexity of the nervous system and the technical difficulties of studying neurological disorders. In this section, we will focus on miRNA related dysregulation in two motor neuron diseases; SMA, and ALS.

\section{mIRNA IN SPINAL MUSCULAR ATROPHY PATHOLOGY}

As it is mentioned above, SMN is a RNA binding protein, which forms a complex with other Gemin proteins, Gemin2-8 (Battle et al., 2006). Among the Gemins, Gemin3 and Gemin4 also bind to Ago2, which served the core protein in RISC and plays a role in miRNA biogenesis (Mourelatos et al., 2002). Moreover, numerous miRNAs bind to Gemin3 in human and murine neuronal cell lines (Dostie et al., 2003). From these reports, we can reason that the SMN complex is involved in miRNA biogenesis and/or function. In fact, expression of miRNAs such as miR-9 and miR-9* were dysregulated in murine embryonic stem cell derived motor neurons harboring a mutation causing SMA (Haramati et al., 2010). However, cellular mechanisms underlying in SMN mediated miRNA expression and/or function is not yet identified.

Dicer is an RNase playing a role in miRNA biogenesis pathway. The enzyme acts on the stem-loop shape of precursor miRNA (pre$\mathrm{miR}$ ) and creates a doubles stranded-miRNAs by cleaving the loop structure off from the pre-miR (Bernstein et al., 2001). It seems that a group of miRNAs get mature by Dicer, while other subset of miRNAs are processed by Ago2 (Cheloufi et al., 2010). Thus, deletion of either Dicer or Ago2 protein in cell may lead to severe impairments in miRNA biogenesis and function. In fact, deletion of Dicer in post-mitotic motor neuron causes motor neuron degeneration, similar to the neuromuscular phenotype observed in mouse model for SMA (Haramati et al., 2010).

\section{mIRNA IN AMYOTROPHIC LATERAL SCLEROSIS PATHOLOGY}

Dysregulation in miRNA expression and miRNA-related pathways are also reported in ALS. The expression of miR-206, a skeletal muscle specific miRNA, was increased in muscle after denervation of sciatic nerve and its deficiency synergistically worsened disease progress in ALS mouse model harboring a disease causing mutation in superoxide dismutase, SOD1. In this study, the elevated expression of miR-206 after denervation promotes reinnervation process at the NMJ via regulating histone deacetylase 4 (HDAC4) and fibroblast growth factor (FGF) pathway (Williams et al., 2009). 
This study is the first report suggesting the role of miRNA for nerve regeneration at the NMJ. Recently, additional report showed that the expression of miR-23a, miR-29b, and miR-455 are elevated in skeletal muscle tissues from ALS patients and this may cause dysregulation in mitochondrial gene expression (Russell et al., 2012). These findings hint us that dysregulated expression of miRNA in muscle cells significantly contributes to ALS pathology.

Another ALS associated gene, TAR DNA-binding protein-43 (TDP-43) is directly involved in miRNA pathway. TDP-43 is a component of the Dicer and Drosha complexes, which are important for miRNA biogenesis. TDP-43 selectively regulates primiRNA processing by binding to primary transcripts of specific miRNAs. It is reported that mutations in TDP-43 gene causes differential expression of mature and functional miRNAs such as miR-132, miR-143 and miR-558 that in turn contribute to ALS pathology. Interestingly, TDP-43 deficiency caused impairment in neurite outgrowth in Neuro2a cells and it was rescued by over-expressing miR-132 (Kawahara and Mieda-Sato, 2012). Additionally, elevated expression of miR-9 is also observed in induced pluripotent stem cell-derived neurons from ALS patient harboring a mutation in TDP-43 (Zhang et al., 2013). Together, these data suggest that TDP-43 is required for neuronal differentiation and neurite outgrowth via regulating miRNA biogenesis pathway and their expression.

Mutations in RNA binding protein FUS/TLS (FUS/translocated in liposarcoma) are also found in ALS patients (Kwiatkowski et al., 2009). Similar to TDP-43, FUS/TLS protein binds to premRNA molecules and determines their fate via regulating splicing, transport, stability, and translation (Lagier-Tourenne et al., 2012). Recently, it has been shown that FUS/TLS promotes biogenesis of specific miRNAs via recruiting Drosha to primary miRNA transcripts. Among them, miRNAs with known function for synaptic plasticity and neuronal development such as miR-132, miR-134, and miR-9 were identified (Morlando et al., 2012). miR-9 regulates axon growth via direct regulation of microtubule-associated protein $1 \mathrm{~b}$ (MAP1B) mRNA translation and miR-132 regulates neuronal morphology and growth by targeting various genes including acetylcholinesterase and Tau (Edbauer et al., 2010; Smith et al., 2011; Dajas-Bailador et al., 2012; Hebert et al., 2012; Shaltiel et al., 2013). miR-134 regulates neuronal development and dendritogenesis in response to neuronal activity (Fiore et al., 2009). These results suggest that mutations in FUS/TLS may lead to disturbance in miRNA biogenesis and function, which contributes to pathological phenotype observed in ALS patients.

In addition to it, miRNA expression in white blood cells from sporadic ALS patients exhibited distinct expression pattern during disease progress. miRNA profiling data from 14 patients and 14 controls showed that expression of miR-338-3p is increased and expression of seven other miRNAs is decreased in leukocyte from ALS patients (De Felice et al., 2012). Since bloods are more accessible than motor neurons from patients, this finding suggests that profiling of miRNA expression from bloods can be used as a diagnostic tool for ALS. Taken together, we can conclude that dysregulated miRNA expression contributes to the ALS pathology and profiling of the miRNA expression can serve as a tool for ALS diagnosis.

\section{SUMMARY AND PERSPECTIVE}

With current advanced genetic tools, genetic causes of motor neuron diseases are getting unveiled. However, pathogenesis of motor neuron disease is extremely complex and not yet fully understood. Due to this reason, efficient cure for motor neuron disease is currently unavailable. Interestingly, even though the genetic causes of the diseases are different, their cellular pathomechanisms share common traits; miRNA biogenesis and expression. Here, we reviewed current knowledge about the role of miRNA in two common motor neuron diseases, SMA and ALS. Dysregulated miRNA expression in neuromuscular system may lead to neurodegeneration and disease pathology. However, the question, how individual miRNAs contribute to development and maintenance of the NMJ and how their dysregulation may cause ALS or SMA, requires further investigation.

\section{ACKNOWLEDGMENT}

Our work is supported by Institute of Human Genetics, University of Cologne.

\section{REFERENCES}

Abelson, J. F., Kwan, K. Y., O’Roak, B. J., Baek, D. Y., Stillman, A. A., Morgan, T. M., et al. (2005). Sequence variants in SLITRK1 are associated with Tourette's syndrome. Science 310, 317-320. doi: 10.1126/science.1116502

Akerblom, M., Sachdeva, R., Barde, I., Verp, S., Gentner, B., Trono, D., et al. (2012). MicroRNA-124 is a subventricular zone neuronal fate determinant. J. Neurosci. 32, 8879-8889. doi: 10.1523/JNEUROSCI.0558-12.2012

Akten, B., Kye, M. J., Hao Le, T., Wertz, M. H., Singh, S., Nie, D., et al. (2011). Interaction of survival of motor neuron (SMN) and HuD proteins with mRNA cpg15 rescues motor neuron axonal deficits. Proc. Natl. Acad. Sci. U.S.A. 108, 10337-10342. doi: 10.1073/pnas.1104928108

Al-Chalabi, A., Jones, A., Troakes, C., King, A., Al-Sarraj, S., and Van Den Berg, L. H. (2012). The genetics and neuropathology of amyotrophic lateral sclerosis. Acta Neuropathol. 124, 339-352. doi: 10.1007/s00401-012-1022-4

Bail, S., Swerdel, M., Liu, H., Jiao, X., Goff, L. A., Hart, R. P., et al. (2010). Differential regulation of microRNA stability. RNA 16, 1032-1039. doi: 10.1261/rna.1851510

Bartel, D. P. (2009). MicroRNAs: target recognition and regulatory functions. Cell 136, 215-233. doi: 10.1016/j.cell.2009.01.002

Battle, D. J., Kasim, M., Yong, J., Lotti, F., Lau, C. K., Mouaikel, J., et al. (2006). The SMN complex: an assembly machine for RNPs. Cold. Spring Harb. Symp. Quant. Biol. 71, 313-320. doi: 10.1101/sqb.2006.71.001

Beghi, E., Logroscino, G., Chio, A., Hardiman, O., Mitchell, D., Swingler, R., et al. (2006). The epidemiology of ALS and the role of population-based registries. Biochim. Biophys. Acta 1762, 1150-1157. doi: 10.1016/j.bbadis.2006. 09.008

Bernstein, E., Caudy, A. A., Hammond, S. M., and Hannon, G. J. (2001). Role for a bidentate ribonuclease in the initiation step of RNA interference. Nature 409, 363-366. doi: 10.1038/35053110

Bernstein, E., Kim, S. Y., Carmell, M. A., Murchison, E. P., Alcorn, H., Li, M. Z., et al. (2003). Dicer is essential for mouse development. Nat. Genet. 35, 215-217. doi: $10.1038 / \mathrm{ng} 1253$

Butovsky, O., Siddiqui, S., Gabriely, G., Lanser, A. J., Dake, B., Murugaiyan, G., et al. (2012). Modulating inflammatory monocytes with a unique microRNA gene signature ameliorates murine ALS. J. Clin. Invest. 122, 3063-3087. doi: 10.1172/JCI62636

Caygill, E. E., and Johnston, L. A. (2008). Temporal regulation of metamorphic processes in Drosophila by the let-7 and miR-125 heterochronic microRNAs. Curr. Biol. 18, 943-950. doi: 10.1016/j.cub.2008.06.020

Chatterjee, S., Fasler, M., Bussing, I., and Grosshans, H. (2011). Target-mediated protection of endogenous microRNAs in C. elegans. Dev. Cell 20, 388-396. doi: 10.1016/j.devcel.2011.02.008

Cheloufi, S., Dos Santos, C. O., Chong, M. M., and Hannon, G. J. (2010). A dicerindependent miRNA biogenesis pathway that requires Ago catalysis. Nature 465, 584-589. doi: 10.1038/nature09092 
Chen, C. Z., Li, L., Lodish, H. F., and Bartel, D. P. (2004). MicroRNAs modulate hematopoietic lineage differentiation. Science 303, 83-86. doi: 10.1126/science. 1091903

Chen, J. A., Huang, Y. P., Mazzoni, E. O., Tan, G. C., Zavadil, J., and Wichterle, H. (2011). Mir-17-3p controls spinal neural progenitor patterning by regulating Olig2/Irx3 cross-repressive loop. Neuron 69, 721-735. doi: 10.1016/j.neuron.2011.01.014

Conaco, C., Otto, S., Han, J. J., and Mandel, G. (2006). Reciprocal actions of REST and a microRNA promote neuronal identity. Proc. Natl. Acad. Sci. U.S.A. 103, 2422-2427. doi: 10.1073/pnas.0511041103

Cougot, N., Bhattacharyya, S. N., Tapia-Arancibia, L., Bordonne, R., Filipowicz, W., Bertrand, E., et al. (2008). Dendrites of mammalian neurons contain specialized P-body-like structures that respond to neuronal activation. J. Neurosci. 28, 13793 13804. doi: 10.1523/JNEUROSCI.4155-08.2008

Crawford, T. O., and Pardo, C. A. (1996). The neurobiology of childhood spinal muscular atrophy. Neurobiol. Dis. 3, 97-110. doi: 10.1006/nbdi.1996.0010

Dajas-Bailador, F., Bonev, B., Garcez, P., Stanley, P., Guillemot, F., and Papalopulu, N (2012). microRNA-9 regulates axon extension and branching by targeting Map1b in mouse cortical neurons. Nat. Neurosci. doi: 10.1038/nn.3082 [Epub ahead of print].

De Felice, B., Guida, M., Coppola, C., De Mieri, G., and Cotrufo, R. (2012). A miRNA signature in leukocytes from sporadic amyotrophic lateral sclerosis. Gene 508, 35-40. doi: 10.1016/j.gene.2012.07.058

DeJesus-Hernandez, M., Mackenzie, I. R., Boeve, B. F., Boxer, A. L., Baker, M., Rutherford, N. J., et al. (2011). Expanded GGGGCC hexanucleotide repeat in noncoding region of C9ORF72 causes chromosome 9p-linked FTD and ALS Neuron 72, 245-256. doi: 10.1016/j.neuron.2011.09.011

Dostie, J., Mourelatos, Z., Yang, M., Sharma, A., and Dreyfuss, G. (2003). Numerous microRNPs in neuronal cells containing novel microRNAs. RNA 9, 180-186. doi: 10.1261/rna.2141503

Edbauer, D., Neilson, J. R., Foster, K. A., Wang, C. F., Seeburg, D. P., Batterton, M. N., etal. (2010). Regulation of synaptic structure and function by FMRP-associated microRNAs miR-125b and miR-132. Neuron 65, 373-384. doi: 10.1016/j.neuron.2010.01.005

Esteller, M. (2011). Non-coding RNAs in human disease. Nat. Rev. Genet. 12, 861-874. doi: 10.1038/nrg3074

Eulalio, A., Huntzinger, E., and Izaurralde, E. (2008). GW182 interaction with Argonaute is essential for miRNA-mediated translational repression and mRNA decay. Nat. Struct. Mol. Biol. 15, 346-353. doi: 10.1038/nsmb.1405

Fallini, C., Zhang, H., Su, Y., Silani, V., Singer, R. H., Rossoll, W., et al. (2011). The survival of motor neuron (SMN) protein interacts with the mRNA-binding protein $\mathrm{HuD}$ and regulates localization of poly(A) mRNA in primary motor neuron axons. J. Neurosci. 31, 3914-3925. doi: 10.1523/JNEUROSCI.3631-10.2011

Fiore, R., Khudayberdiev, S., Christensen, M., Siegel, G., Flavell, S. W., Kim, T. K., et al. (2009). Mef2-mediated transcription of the miR379-410 cluster regulates activity-dependent dendritogenesis by fine-tuning Pumilio2 protein levels. EMBO J. 28, 697-710. doi: 10.1038/emboj.2009.10

Forterre, A., Jalabert, A., Chikh, K., Pesenti, S., Euthine, V., Granjon, A., et al. (2013) Myotube-derived exosomal miRNAs downregulate Sirtuin 1 in myoblasts during muscle cell differentiation. Cell Cycle 13, 78-89. doi: 10.4161/cc.26808

Fruhbeis, C., Frohlich, D., Kuo, W. P., Amphornrat, J., Thilemann, S., Saab, A. S., et al. (2013). Neurotransmitter-triggered transfer of exosomes mediates oligodendrocyte-neuron communication. PLoS Biol. 11:e1001604. doi 10.1371/journal.pbio.1001604

Gao, J., Wang, W. Y., Mao, Y. W., Graff, J., Guan, J. S., Pan, L., et al. (2010). A novel pathway regulates memory and plasticity via SIRT1 and miR-134. Nature 466, 1105-1109. doi: 10.1038/nature09271

Gao, P., Tchernyshyov, I., Chang, T. C., Lee, Y. S., Kita, K., Ochi, T., et al. (2009). c-Myc suppression of miR-23a/b enhances mitochondrial glutaminase expression and glutamine metabolism. Nature 458, 762-765. doi: 10.1038/nature07823

Gaughwin, P. M., Ciesla, M., Lahiri, N., Tabrizi, S. J., Brundin, P., and Bjorkqvist, M. (2011). Hsa-miR-34b is a plasma-stable microRNA that is elevated in pre-manifest Huntington's disease. Hum. Mol. Genet. 20, 2225-2237. doi: $10.1093 / \mathrm{hmg} / \mathrm{ddr} 111$

Grange, C., Tapparo, M., Collino, F., Vitillo, L., Damasco, C., Deregibus, M. C., et al. (2011). Microvesicles released from human renal cancer stem cells stimulate angiogenesis and formation of lung premetastatic niche. Cancer Res. 71, 53465356. doi: 10.1158/0008-5472.CAN-11-0241
Haramati, S., Chapnik, E., Sztainberg, Y., Eilam, R., Zwang, R., Gershoni, N., et al. (2010). miRNA malfunction causes spinal motor neuron disease. Proc. Natl. Acad. Sci. U.S.A. 107, 13111-13116. doi: 10.1073/pnas.1006151107

Hatfield, S. D., Shcherbata, H. R., Fischer, K. A., Nakahara, K., Carthew, R. W., and Ruohola-Baker, H. (2005). Stem cell division is regulated by the microRNA pathway. Nature 435, 974-978. doi: 10.1038/nature03816

Hebert, S. S., Sergeant, N., and Buee, L. (2012). MicroRNAs and the regulation of Tau metabolism. Int. J. Alzheimers Dis. 2012, 406561. doi: 10.1155/2012/406561

Hornstein, E., Mansfield, J. H., Yekta, S., Hu, J. K., Harfe, B. D., McManus, M. T., et al. (2005). The microRNA miR-196 acts upstream of Hoxb8 and Shh in limb development. Nature 438, 671-674. doi: 10.1038/nature04138

Houbaviy, H. B., Murray, M. F., and Sharp, P. A. (2003). Embryonic stem cell-specific MicroRNAs. Dev. Cell 5, 351-358. doi: 10.1016/S1534-5807(03)00227-2

Hu, J. Z., Huang, J. H., Zeng, L., Wang, G., Cao, M., and Lu, H. B. (2013). Antiapoptotic effect of microRNA-21 after contusion spinal cord injury in rats. $J$. Neurotrauma 30, 1349-1360. doi: 10.1089/neu.2012.2748

Huntzinger, E., and Izaurralde, E. (2011). Gene silencing by microRNAs: contributions of translational repression and mRNA decay. Nat. Rev. Genet. 12, 99-110. doi: $10.1038 / \mathrm{nrg} 2936$

Iio, A., Takagi, T., Miki, K., Naoe, T., Nakayama, A., and Akao, Y. (2013). DDX6 post-transcriptionally down-regulates miR-143/145 expression through host gene NCR143/145 in cancer cells. Biochim. Biophys. Acta 1829, 1102-1110. doi: 10.1016/j.bbagrm.2013.07.010

Jansson, M. D., and Lund, A. H. (2012). MicroRNA and cancer. Mol. Oncol. 6, 590-610. doi: 10.1016/j.molonc.2012.09.006

Jin, P., Zarnescu, D. C., Ceman, S., Nakamoto, M., Mowrey, J., Jongens, T. A., et al. (2004). Biochemical and genetic interaction between the fragile X mental retardation protein and the microRNA pathway. Nat. Neurosci. 7, 113-117. doi: $10.1038 / \mathrm{nn} 1174$

Kawahara, Y., and Mieda-Sato, A. (2012). TDP-43 promotes microRNA biogenesis as a component of the Drosha and Dicer complexes. Proc. Natl. Acad. Sci. U.S.A. 109, 3347-3352. doi: 10.1073/pnas.1112427109

Kim, V. N., Han, J., and Siomi, M. C. (2009). Biogenesis of small RNAs in animals. Nat. Rev. Mol. Cell Biol. 10, 126-139. doi: 10.1038/nrm2632

Krol, J., Loedige, I., and Filipowicz, W. (2010). The widespread regulation of microRNA biogenesis, function and decay. Nat. Rev. Genet. 11, 597-610. doi: $10.1038 / \operatorname{nrg} 2843$

Kwiatkowski, T. J. Jr., Bosco, D. A., Leclerc, A. L., Tamrazian, E., Vanderburg, C. R., Russ, C., et al. (2009). Mutations in the FUS/TLS gene on chromosome 16 cause familial amyotrophic lateral sclerosis. Science 323, 1205-1208. doi: $10.1126 /$ science. 1166066

Kye, M. J., Liu, T., Levy, S. F., Xu, N. L., Groves, B. B., Bonneau, R., et al. (2007). Somatodendritic microRNAs identified by laser capture and multiplex RT-PCR. RNA 13, 1224-1234. doi: 10.1261/rna.480407

Lagier-Tourenne, C., Polymenidou, M., Hutt, K. R., Vu, A. Q., Baughn, M., Huelga, S. C., et al. (2012). Divergent roles of ALS-linked proteins FUS/TLS and TDP43 intersect in processing long pre-mRNAs. Nat. Neurosci. 15, 1488-1497. doi: $10.1038 / \mathrm{nn} .3230$

Landthaler, M., Gaidatzis, D., Rothballer, A., Chen, P. Y., Soll, S. J., Dinic, L., et al. (2008). Molecular characterization of human Argonaute-containing ribonucleoprotein complexes and their bound target mRNAs. RNA 14, 2580-2596. doi: 10.1261/rna.1351608

Lee, S. T., Chu, K., Jung, K. H., Kim, J. H., Huh, J. Y., Yoon, H., et al. (2012). miR-206 regulates brain-derived neurotrophic factor in Alzheimer disease model. Ann. Neurol. 72, 269-277. doi: 10.1002/ana.23588

Lefebvre, S., Burglen, L., Reboullet, S., Clermont, O., Burlet, P., Viollet, L., etal. (1995). Identification and characterization of a spinal muscular atrophy-determining gene. Cell 80, 155-165. doi: 10.1016/0092-8674(95)90460-3

Liang, C., Zhu, H., Xu, Y., Huang, L., Ma, C., Deng, W., et al. (2012). MicroRNA-153 negatively regulates the expression of amyloid precursor protein and amyloid precursor-like protein 2. Brain Res. 1455, 103-113. doi: 10.1016/j.brainres.2011.10.051

Liu, C. M., Wang, R. Y., Saijilafu, Jiao, Z. X., Zhang, B. Y., and Zhou, F. Q. (2013). MicroRNA-138 and SIRT1 form a mutual negative feedback loop to regulate mammalian axon regeneration. Genes Dev. 27, 1473-1483. doi: 10.1101/gad.209619.112

Morita, S., Horii, T., Kimura, M., Goto, Y., Ochiya, T., and Hatada, I. (2007). One Argonaute family member, Eif2c2 (Ago2), is essential for development and 
appears not to be involved in DNA methylation. Genomics 89, 687-696. doi: 10.1016/j.ygeno.2007.01.004

Morlando, M., Dini Modigliani, S., Torrelli, G., Rosa, A., Di Carlo, V., Caffarelli, E., et al. (2012). FUS stimulates microRNA biogenesis by facilitating co-transcriptional Drosha recruitment. EMBO J. 31, 4502-4510. doi: 10.1038/emboj.2012.319

Mourelatos, Z., Dostie, J., Paushkin, S., Sharma, A., Charroux, B., Abel, L., et al. (2002). miRNPs: a novel class of ribonucleoproteins containing numerous microRNAs. Genes Dev. 16, 720-728. doi: 10.1101/gad.974702

Naguibneva, I., Ameyar-Zazoua, M., Polesskaya, A., Ait-Si-Ali, S., Groisman, R., Souidi, M., et al. (2006). The microRNA miR-181 targets the homeobox protein Hox-A11 during mammalian myoblast differentiation. Nat. Cell Biol. 8, 278-284. doi: $10.1038 /$ ncb 1373

Natera-Naranjo, O., Aschrafi, A., Gioio, A. E., and Kaplan, B. B. (2010). Identification and quantitative analyses of microRNAs located in the distal axons of sympathetic neurons. RNA 16, 1516-1529. doi: 10.1261/rna.1833310

Nesler, K. R., Sand, R. I., Symmes, B. A., Pradhan, S. J., Boin, N. G., Laun, A. E., et al. (2013). The miRNA pathway controls rapid changes in activity-dependent synaptic structure at the Drosophila melanogaster neuromuscular junction. PLoS ONE 8:e68385. doi: 10.1371/journal.pone.0068385

Otaegi, G., Pollock, A., Hong, J., and Sun, T. (2011a). MicroRNA miR-9 modifies motor neuron columns by a tuning regulation of FoxP1 levels in developing spinal cords. J. Neurosci. 31, 809-818. doi: 10.1523/JNEUROSCI.4330-10. 2011

Otaegi, G., Pollock, A., and Sun, T. (2011b). An optimized sponge for microRNA miR-9 affects spinal motor neuron development in vivo. Front. Neurosci. 5:146 doi: 10.3389/fnins.2011.00146

Packer, A. N., Xing, Y., Harper, S. Q., Jones, L., and Davidson, B. L. (2008) The bifunctional microRNA miR-9/miR-9* regulates REST and CoREST and is downregulated in Huntington's disease. J. Neurosci. 28, 14341-14346. doi: 10.1523/JNEUROSCI.2390-08.2008

Pearn, J. (1980). Classification of spinal muscular atrophies. Lancet 1, 919-922. doi: 10.1016/S0140-6736(80)90847-8

Pellizzoni, L., Kataoka, N., Charroux, B., and Dreyfuss, G. (1998). A novel function for SMN, the spinal muscular atrophy disease gene product, in pre-mRNA splicing. Cell 95, 615-624. doi: 10.1016/S0092-8674(00)81632-3

Piazzon, N., Rage, F., Schlotter, F., Moine, H., Branlant, C., and Massenet, S. (2008). In vitro and in cellulo evidences for association of the survival of motor neuron complex with the fragile X mental retardation protein. J. Biol. Chem. 283, 5598-5610. doi: 10.1074/jbc.M707304200

Pratt, A. J., Getzoff, E. D., and Perry, J. J. (2012). Amyotrophic lateral sclerosis: update and new developments. Degener. Neurol. Neuromuscul. Dis. 2012, 1-14.

Renton, A. E., Majounie, E., Waite, A., Simon-Sanchez, J., Rollinson, S. Gibbs, J. R., et al. (2011). A hexanucleotide repeat expansion in C9ORF72 is the cause of chromosome 9p21-linked ALS-FTD. Neuron 72, 257-268. doi: 10.1016/j.neuron.2011.09.010

Rosen, D. R., Siddique, T., Patterson, D., Figlewicz, D. A., Sapp, P., Hentati, A., et al. (1993). Mutations in $\mathrm{Cu} / \mathrm{Zn}$ superoxide dismutase gene are associated with familial amyotrophic lateral sclerosis. Nature 362, 59-62. doi: 10.1038/362059a0

Ruegger, S., and Grosshans, H. (2012). MicroRNA turnover: when, how, and why. Trends Biochem. Sci. 37, 436-446. doi: 10.1016/j.tibs.2012.07.002

Russell, A. P., Wada, S., Vergani, L., Hock, M. B., Lamon, S., Leger, B., et al. (2012). Disruption of skeletal muscle mitochondrial network genes and miRNAs in amyotrophic lateral sclerosis. Neurobiol. Dis. 49C, 107-117. doi: 10.1016/j.nbd.2012.08.015

Sasaki, Y., Gross, C., Xing, L., Goshima, Y., and Bassell, G. J. (2013). Identification of axon-enriched microRNAs localized to growth cones of cortical neurons. Dev Neurobiol. doi: 10.1002/dneu.22113 [Epub ahead of print].

Shaltiel, G., Hanan, M., Wolf, Y., Barbash, S., Kovalev, E., Shoham, S., et al. (2013). Hippocampal microRNA-132 mediates stress-inducible cognitive deficits through its acetylcholinesterase target. Brain Struct. Funct. 218, 59-72. doi: 10.1007/s00429-011-0376-z

Sharma, P., Schiapparelli, L., and Cline, H. T. (2013). Exosomes function in cell-cell communication during brain circuit development. Curr. Opin. Neurobiol. 23, 997-1004. doi: 10.1016/j.conb.2013.08.005

Smith, P. Y., Delay, C., Girard, J., Papon, M. A., Planel, E., Sergeant, N., et al. (2011). MicroRNA-132 loss is associated with tau exon 10 inclusion in progressive supranuclear palsy. Hum. Mol. Genet. 20, 4016-4024. doi: 10.1093/hmg/ddr330
Soldevilla, B., Rodriguez, M., San Millan, C., Garcia, V., Fernandez-Perianez, R., GilCalderon, B., et al. (2013). Tumor-derived exosomes are enriched in DeltaNp73, which promotes oncogenic potential in acceptor cells and correlates with patient survival. Hum. Mol. Genet. 23, 467-478. doi: 10.1093/hmg/ddt437

Strickland, I. T., Richards, L., Holmes, F. E., Wynick, D., Uney, J. B., and Wong, L. F. (2011). Axotomy-induced miR-21 promotes axon growth in adult dorsal root ganglion neurons. PLoS ONE 6:e23423. doi: 10.1371/journal.pone.0023423

Sun, K., Westholm, J. O., Tsurudome, K., Hagen, J. W., Lu, Y., Kohwi, M., et al. (2012). Neurophysiological defects and neuronal gene deregulation in Drosophila mir-124 mutants. PLoS Genet. 8:e1002515. doi: 10.1371/journal.pgen.1002515

Tadesse, H., Deschenes-Furry, J., Boisvenue, S., and Cote, J. (2008). KH-type splicing regulatory protein interacts with survival motor neuron protein and is misregulated in spinal muscular atrophy. Hum. Mol. Genet. 17, 506-524. doi: $10.1093 / \mathrm{hmg} / \mathrm{ddm} 327$

Tsurudome, K., Tsang, K., Liao, E. H., Ball, R., Penney, J., Yang, J. S., et al. (2010). The Drosophila miR-310 cluster negatively regulates synaptic strength at the neuromuscular junction. Neuron 68, 879-893. doi: 10.1016/j.neuron.2010.11.016

Valadi, H., Ekstrom, K., Bossios, A., Sjostrand, M., Lee, J. J., and Lotvall, J. O. (2007). Exosome-mediated transfer of mRNAs and microRNAs is a novel mechanism of genetic exchange between cells. Nat. Cell Biol. 9, 654-659. doi: 10.1038/ncb1596

Wang, Y., Medvid, R., Melton, C., Jaenisch, R., and Blelloch, R. (2007). DGCR8 is essential for microRNA biogenesis and silencing of embryonic stem cell selfrenewal. Nat. Genet. 39, 380-385. doi: 10.1038/ng1969

Williams, A. H., Valdez, G., Moresi, V., Qi, X., McAnally, J., Elliott, J. L., et al. (2009). MicroRNA-206 delays ALS progression and promotes regeneration of neuromuscular synapses in mice. Science 326, 1549-1554. doi: $10.1126 /$ science. 1181046

Wirth, B., Brichta, L., and Hahnen, E. (2006). Spinal muscular atrophy: from gene to therapy. Semin. Pediatr. Neurol. 13, 121-131. doi: 10.1016/j.spen.2006.06.008

Wirth, B., Garbes, L., and Riessland, M. (2013). How genetic modifiers influence the phenotype of spinal muscular atrophy and suggest future therapeutic approaches. Curr. Opin. Genet. Dev. 23, 330-338. doi: 10.1016/j.gde.2013.03.003

Wu, D., and Murashov, A. K. (2013). MicroRNA-431 regulates axon regeneration in mature sensory neurons by targeting the Wnt antagonist Kremen1. Front. Mol. Neurosci. 6:35. doi: 10.3389/fnmol.2013.00035

Wu, D., Raafat, A., Pak, E., Clemens, S., and Murashov, A. K. (2012). DicermicroRNA pathway is critical for peripheral nerve regeneration and functional recovery in vivo and regenerative axonogenesis in vitro. Exp. Neurol. 233, 555-565. doi: 10.1016/j.expneurol.2011.11.041

Xiao, C., Calado, D. P., Galler, G., Thai, T. H., Patterson, H. C., Wang, J., et al. (2007). MiR-150 controls B cell differentiation by targeting the transcription factor c-Myb. Cell 131, 146-159. doi: 10.1016/j.cell.2007.07.021

Yamazaki, T., Chen, S., Yu, Y., Yan, B., Haertlein, T. C., Carrasco, M. A., et al. (2012) FUS-SMN protein interactions link the motor neuron diseases ALS and SMA. Cell Rep. 2, 799-806. doi: 10.1016/j.celrep.2012.08.025

Yu, Y. M., Gibbs, K. M., Davila, J., Campbell, N., Sung, S., Todorova, T. I., et al. (2011). MicroRNA miR-133b is essential for functional recovery after spinal cord injury in adult zebrafish. Eur. J. Neurosci. 33, 1587-1597. doi: 10.1111/j.14609568.2011.07643.x

Zekri, L., Huntzinger, E., Heimstadt, S., and Izaurralde, E. (2009). The silencing domain of GW182 interacts with PABPC1 to promote translational repression and degradation of microRNA targets and is required for target release. Mol. Cell. Biol. 29, 6220-6231. doi: 10.1128/MCB.01081-09

Zhang, Z., Almeida, S., Lu, Y., Nishimura, A. L., Peng, L., Sun, D., et al. (2013). Downregulation of MicroRNA-9 in iPSC-derived neurons of FTD/ALS patients with TDP-43 mutations. PLoS ONE 8:e76055. doi: 10.1371/journal.pone.0076055

Zhou, R., Yuan, P., Wang, Y., Hunsberger, J. G., Elkahloun, A., Wei, Y., et al. (2009). Evidence for selective microRNAs and their effectors as common long-term targets for the actions of mood stabilizers. Neuropsychopharmacology 34, 1395-1405. doi: 10.1038/npp.2008.131

Zhu, H., Bhattacharyya, B. J., Lin, H., and Gomez, C. M. (2013). Skeletal muscle calpain acts through nitric oxide and neural miRNAs to regulate acetylcholine release in motor nerve terminals. J. Neurosci. 33, 7308-7324. doi: 10.1523/JNEUROSCI.0224-13.2013

Conflict of Interest Statement: The authors declare that the research was conducted in the absence of any commercial or financial relationships that could be construed as a potential conflict of interest. 
Received: 18 November 2013; accepted: 10 January 2014; published online: 30 January 2014

Citation: Kye MJ and Gonçalves ICG (2014) The role of miRNA in motor neuron disease. Front. Cell. Neurosci. 8:15. doi: 10.3389/fncel.2014. 00015

This article was submitted to the journal Frontiers in Cellular Neuroscience.
Copyright (c) 2014 Kye and Gonçalves. This is an open-access article distributed under the terms of the Creative Commons Attribution License (CC BY). The use, distribution or reproduction in other forums is permitted, provided the original author(s) or licensor are credited and that the original publication in this journal is cited, in accordance with accepted academic practice. No use, distribution or reproduction is permitted which does not comply with these terms. 